\title{
Impact of the 2019 volleyball proliga event on audience satisfaction and loyalty
}

\author{
Faisal S Sandrima ${ }^{\text {abcde } *\left(\mathbb{C}, \text { Yudik Prasetyo }^{\text {cde }} \text { (1) }\right.}$, Ali Algifari ${ }^{\text {abc }}$ \\ Universitas Negeri Yogyakarta, Indonesia
}

Received: 25 July 2021; Accepted 17 September 2021; Published 15 December 2021

Ed 2021; 6(3): 403-410

\begin{abstract}
The quality of service and the performance of the management team in a sporting event is thought to be able to influence audience satisfaction, so that these two things become important factors in the success of organizing sports matches. The purpose of this study was to determine and describe the impact of organizing sporting events on audience satisfaction and loyalty based on the quality of service and performance of the organizing committee in managing sports events. The study used a descriptive approach with qualitative and quantitative methods. 64 spectators were randomly selected from all the spectators who attended the volleyball proliga sport event held at GOR Amongrogo, Yogyakarta City. Data collection techniques uses a questionnaire. The data analysis technique used PLS - SEM. The results of the study found that there was an influence of service quality and performance of the match management team on audience satisfaction and loyalty. These results indicate that the indicators of the implementation of sports activities are measured by the satisfaction and loyalty level of the audience following the match with the service quality and management of the organizers as influencing factors.
\end{abstract}

Keywords: Sport event; service quality; management; satisfaction; audience loyalty

https://doi.org/10.25299/sportarea. 2021.vol6(3).7516

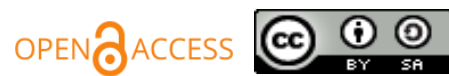

Copyright (C 2021 Faisal S Sandrima, Yudik Prasetyo, Ali Algifari

Corresponding Author: Faisal S Sandrima, Postgraduate Program of Sport Science, Universitas Negeri Yogyakarta, Yogyakarta, Indonesia

Email: fsandrima77@uny.ac.id

How to Cite: Sandrima, F. S., Prasetyo, Y., \& Algifari, A. (2021). Impact of the 2019 volleyball proliga event on audience satisfaction and loyalty. Journal Sport Area, 6(3), 403-410. https://doi.org/10.25299/sportarea. 2021.vol6(3).7516

Authors' Contribution: a - Study Design; b - Data Collection; c - Statistical Analysis; d - Manuscript Preparation; e - Funds Collection

\section{INTRODUCTION}

Research on the impact of a sports championship or sport industry has never been studied. The possible impact is an increase in the mobilization of people to the destination area for the championship, and an increase in economic activity in that area. Several indicators are proposed to influence the planning of a good sports activity, such as satisfaction to the emergence of audience loyalty. Research on the impact of the sports industry was carried out by Ranjan (2016) but the two studies have not discussed the indicators that can influence the impact of the sports industry, especially from the audience side. The sports industry has a large economic impact through the mobilization of people or the gathering of several people related to the event, such as event sponsors, traders, athletes, transportation parties, and other sports lovers to enjoy matches or recreation (Kersulić et al., 2020). The scale of organizing sports activities depends on the type of 
athletes who participate in them, professional or amateur, or even the nature of the organization of these activities, formal or informal. The implementation of sports activities is accompanied by management of activities which include funding, committees, arrangement of activities, and promotion of activities, to the presence of crowds (Schnitzer et al., 2017). The implementation of sports activities is managed by event management. The purpose of organizing sports activities carried out by an organization is to manage the roles and responsibilities assigned in carrying out certain tasks, so that the implementation of these sports activities runs successfully and in accordance with the planned procedures (Ranjan, 2016).

Along with the increasing number of events held, one of which is in the field of sports, it is necessary to raise awareness to develop event management professionalism that is able to create, organize, and manage events better. A sporting activity will get a place in people's hearts if all that is offered is in accordance with what they want. In organizing sports activities, clear and measurable themes, and goals are needed so that it is very easy to measure success. For example, the success of organizing sports activities is measured by the level of security in the organization, because with controlled security, all matches run smoothly and can be enjoyed by spectators. There is even a benchmark that the success of organizing sports activities is the satisfaction and loyalty of the audience in participating in the matches that are held. The implementation of sports activities has many positive impacts for the area or place that organizes them, such as economic, social, and psychological impacts. Moreover, for the construction and development of various sports fields, it will be expanded, so that it can absorb local workers in its development. From the organizer's point of view, the audience is the most potential target in providing income from the activities held. So it is very important to know the characteristics of a spectator by paying attention to the level of security, facilities for spectators, infrastructure, and ticket prices provided, to match their wishes. Some of the reviews above show that the evaluation of the implementation of sports activities is based on event management, service quality, satisfaction, and audience loyalty (Alguacil et al., 2018; Beyrami \& Najafzadeh, 2015; Dorofeeva, 2021).

Event management aims to manage the organization of sports activities to be packaged as well as possible, so that the sustainability and quality of the organization of activities can be evaluated and improved (Ranjan, 2016). Organizer identification and involvement positively affect perceptions of event quality and satisfaction (García-Fernández et al., 2018). In particular, die-hard fans are very satisfied and feel a more positive quality of service (Xiao et al., 2020). The organization of sports activities can have a positive impact in terms of economy, environment, and social, if the event organizer has managed the event effectively and efficiently in accordance with the rules and pays attention to the quality of service and audience satisfaction such as facilities, security, environmental cleanliness, on the ticket price paid (Moreno et al., 2016; Wang et al., 2018; Zhuo et al., 2020). The quality of services provided by the management of the organizers provides added value to the sports activities held (Kersulić et al., 2020). Evaluation of service quality leads to customer satisfaction (Oueslati et al., 2017). The determinants of service quality are influenced by facilities, infrastructure, and security. This affects customer satisfaction on the quality of service provided by the service provider (sports event organizer) and has an impact on efforts to create audience loyalty for a sports activity.

The provision of high quality services is very important for the progress and income of the organization of activities (To-aj \& Suksa-ard, 2020). Satisfied spectators tend to enjoy matches that are held for a long time in the activity area (stadium stands) (Savić et al., 2018). A large number of spectators is an indicator of the success of a sporting activity being held. Basically there is a close relationship between service quality and the level of audience satisfaction (Dorofeeva, 2021; Hussin, 2018). Audience satisfaction is the feeling of satisfaction received after getting something for what is expected, so that later the audience will return to watching sports activities which are held willingly and without coercion, even having to buy tickets at expensive prices. Loyalty is a commitment to always follow the development of sports activities continuously (Wymer \& Rundle-Thiele, 2016). Audience loyalty can be used as a basis or assessment of policies for organizing sports activities in making decisions to increase or decrease the facilities obtained (Yeung et al., 2012). Service quality serves as a standard for organizers to find out whether the action plans and strategies that have been used to improve service quality can be perceived well by the audience, so that 
it will have an impact on satisfaction for the audience themselves. Therefore, satisfaction is one of the indicators that aims to evaluate what is actually received, expected, needed by the audience so that the audience will come back again to watch the sport activities held (Hadian et al., 2020; Hebles et al., 2020). Apart from the above factors, the arrival of idol players for the audience is the main attraction that makes them come back to enjoy the game. With the existence of large sports activities are expected to have a positive impact for all people who enjoy them. The novelty offered in the research is an in-depth analysis of the impact of the implementation of sports championships which include: satisfaction, fan loyalty, quality of organizer management, match support infrastructure, and match safety. This research is very important because the results show the level of success and shortcomings of the 2019 Volleyball Proliga held in the city of Yogyakarta, so it is a consideration to improve it. Finally, the information from the results of this research is especially useful to help anyone who manages an event, and can be used as a reference for further research.

\section{METHOD}

This research is a descriptive study using a mixed method of qualitative and quantitative approaches. The population in this study were all spectators who attended the proliga volleyball sports event held at GOR Amongrogo, Yogyakarta City. The sample of this study was determined by means of simple random sampling, so that the selected sample consisted of 64 viewers. Data collection techniques using a questionnaire of structural equation modeling (Moreno et al., 2016). The data analysis technique used PLS SEM. The hope of the research is to show the impact on the 2018 volleyball pro league sports event through service quality variables, the performance of the organizing team and several influencing indicators such as security, facilities, tariff values, and infrastructure.

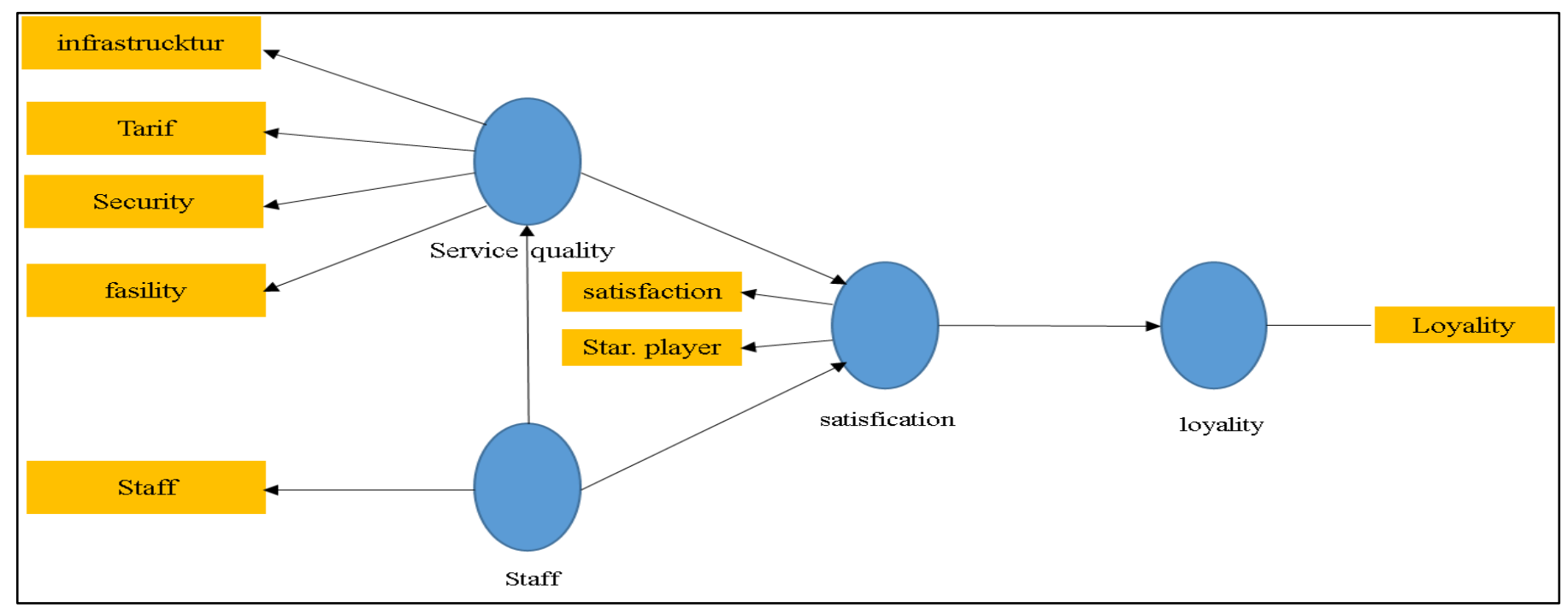

Figure 1. Research Design

\section{RESULTS AND DISCUSSION}

There were 64 samples have provided research data through a questionnaire that has been given. The following are the results of the measurement instruments used to describe audience satisfaction and loyalty.

Tabel 1. Construct Reliability and Validity

\begin{tabular}{lcrrr}
\hline & Alpha & rhoA & Composite reliability & AVE \\
\hline Loyality & 1.000 & 1.000 & 1.000 & 1.000 \\
Satisfaction & 0.780 & 0.782 & 0.901 & 0.819 \\
Service Quality & 0.755 & 0.761 & 0.845 & 0.577 \\
Staff & 1.000 & 1.000 & 1.000 & 1.000 \\
\hline
\end{tabular}


In this study, all composite reliability values were above the threshold of 0.70 , indicating that the combined reliability of each reflective latent variable was acceptable and confirmed the reliability of the construct. Construct validity is the degree to which an item measures what it is expected to measure. The construct validity test was passed by testing the convergent validity and discriminant validity. Convergent validity is the extent to which an AVE measure reflects the average communality for each latent factor with a value greater than 0.50 . Table 1 shows that all AVE values are above 0.50 , it means that the convergent validity of each latent factor is acceptable.

Tabel 2. Collinearity Assessment (VIF)

\begin{tabular}{cc}
\hline Variable & VIF \\
\hline Infrastructure & $\mathbf{1 . 5 2 2}$ \\
Loyality & $\mathbf{1 . 0 0 0}$ \\
Tariff & $\mathbf{1 . 9 5 9}$ \\
Satisfaction & $\mathbf{1 . 6 9 1}$ \\
Security & $\mathbf{1 . 4 3 7}$ \\
Staff & $\mathbf{1 . 0 0 0}$ \\
Star palyer & $\mathbf{1 . 6 9 1}$ \\
\hline
\end{tabular}

Collinearity testing is done by using the variance inflation factor (VIF). Table 2 shows that all the proposed variables have a VIF value far below the threshold value of 5, it means that there is no collinearity problem. Service quality $(0.150)$ does not directly affect the satisfaction of the audience which is presented by a small correlation between these variables, but it is influenced through the quality of staff performance with audience satisfaction (0.726). The influence of staff performance also affects the quality of service provided (0.804). This shows that service quality is influenced by staff performance and has a big role in audience satisfaction. The final result obtained is audience satisfaction in which there are indicators of star players $(0.725)$ which have a big role in life. The following is a chart that explains the relationship of each variable in this study:

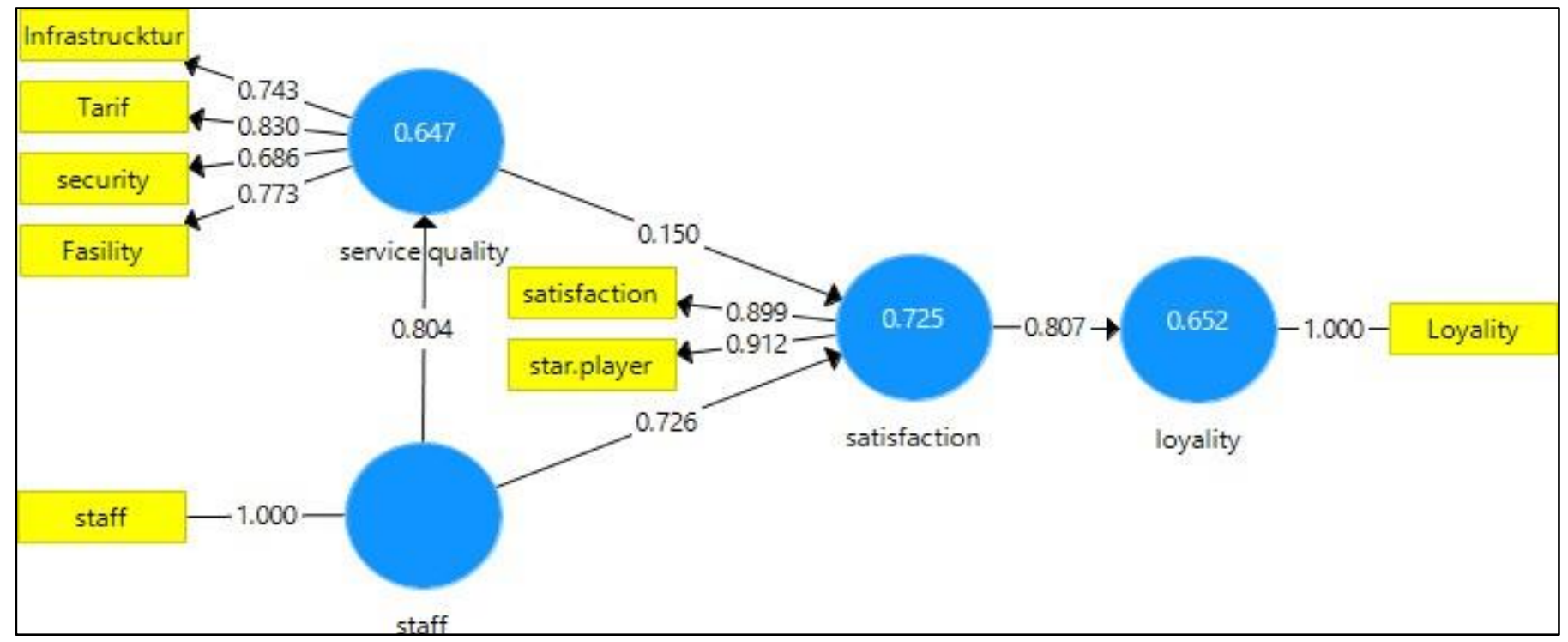

Figure 2. Significance Testing Results of the Structural Model Path Coefficients

Figure 2 presents the relationship between indicators and research variables which explains whether there is an influence of indicators on variables or the influence of variables on other variables. Figure 2 shows that service quality is positively influenced by infrastructure (0.743), tariff (0.830), safety or security $(0.686)$ and facility $(0.733)$ with a strong correlation. 
The results of the research analysis show that the quality of service for organizing sports activities is influenced by indicators of infrastructure, security, tariff rates, and the performance of the organizing committee. The results of the analysis prove that there is a positive and significant effect between service quality and the performance of the organizing committee on audience satisfaction. In addition, indicators of the influence of professional athletes also have an impact on audience loyalty. These results explain that in order to achieve audience loyalty, spectators must be satisfied with the service quality and performance of the sports event organizing team so that they have an interest in coming back to the next sporting activity.

The focus of this research is how the organization of a sports activity can provide satisfaction for the audience to form a loyalty. Audience satisfaction is influenced by the performance of the athletes or teams competing, this parameter is proven when there are two big teams competing, because the team consists of well-known professional athletes (Lee \& Kang, 2015). This can be seen in the action of the audience cheering in the stands when several players perform certain techniques. This satisfaction can increase when the organizers provide quality services such as comfortable stands or bright field lights. Service quality has a significant effect on audience satisfaction, so there is a sense of wanting to always follow the development of sports activities carried out (Yürük et al., 2017). Therefore, it is necessary to have an appropriate strategy or technical service for the implementation of sports activities in accordance with the characteristics of the sports being held. When the audience feels satisfied, then the next step is how to make them have high loyalty to the activity, at least to the supported team/group. The loyalty of supporters or spectators in stadiums holding sports matches begins with the satisfaction of the audience with their expectations of seeing the matches being held. These expectations are based on the performance of the competing athletes, the appropriate ticket prices, and the quality of service (Du et al., 2015).

Audience loyalty is usually shown by the use of a merchandise, such as a supported team jersey, or it can be in the form of a support song. The identity of a team in the form of a jersey has a positive and significant effect on increasing the loyalty of supporters (audiences), so to maintain this loyalty, the management of a sports organization must provide good service quality, one of which is through the sale of club merchandise (Benesbordi \& Esmaeili, 2020). The loyalty of the audience is proof that they have felt satisfaction with the performance of the competing team, usually the loyalty of the audience is shown in the form of a support song in the stadium (Lee et al., 2013). The existence of brand merchandise gives a sense of satisfaction of the audience (visitors) to the organization of an activity (Chen et al., 2020). The research shows that audience loyalty is evidenced by the presence of supported team identity merchandise and support in the form of singing. Lee and Kang (2015) shows that supporter loyalty can be proven by following the development of team information, individual players to the match schedule to be implemented. Audience loyalty can be increased through audiences between club management and audience group representatives to discuss the progress of the club's performance (Lischka \& Messerli, 2016).

The need is a strategy for developing indicators of organizing a sports activity, in order to achieve satisfaction and loyalty from the audience (Gholipour \& Moradi, 2021). Interventions to increase audience satisfaction and loyalty can be carried out by identifying the desired needs, such as team logos, stadium facilities, and affordable ticket prices (Silveira et al., 2019). Spectators of sports matches can indirectly have maximum satisfaction when there is a commentator on the course of the match (Lee et al., 2016). The performance of the star players with an interesting match was the reason for the audience to watch the match until the end (Theodorakis et al., 2015; Zhang et al., 2014). The other side that can be developed from the existence of sports championships is the tourism sector (Kaplanidou, 2021). Tourism destinations can develop with the presence of supporters of a sports championship that is held over a long period of time. With a series of sports championships, supporters usually stay temporarily in the area, so they take advantage of tourism as a second destination for the existence of a sports championship (Buning, 2019). The large number of visitors, most of whom are supporters at sports championships, can introduce local products, so that the impact experienced by indigenous people from the region is increasing income from the tourism sector.

The research shows that intervention in the implementation of sports activities can be carried out through service quality, such as supporting facilities for organizing activities that meet safety standards, affordable 
ticket costs, competing teams consisting of players who are known to the audience. In addition, the presence of a match commentator adds to the interesting course of the match. The end of the discussion from the results of this study shows that the quality of service and the existence of good management are very important to pay attention to.

\section{CONCLUSION}

Service quality and performance of the organizing team have a positive and significant influence on audience satisfaction. Other influencing indicators include: facilities, security, value of entry fees, and supporting infrastructure. Future research is expected to be able to examine other variables such as gender differences, quality of access, quality of venues, quality of matches, and audience views. These variables have the opportunity to produce new findings that have never been studied in relation to increasing audience satisfaction and loyalty in organizing sports activities. The limitation of this study lies in the relatively small number of samples, so that generalizations on the results of the study can be improved in future studies with larger samples and/or in championships other than Proliga (Volleyball), it could be football or basketball, etc.

\section{ACKNOWLEDGMENT}

I would like to thank my friends who helped in this research, without you my research could not run smoothly. In addition, I also thank my lecturers who are patient in guiding.

\section{CONFLICT OF INTEREST}

The authors have no conflict of interest to declare.

\section{REFERENCES}

Alguacil, M., Pérez-Campos, C., \& González-Serrano, M. H. (2018). Study of spectator satisfaction at a major athletics event. Journal of Physical Education and Sport, 18, 1256-1264. https://doi.org/10.7752/jpes.2018.s3187

Benesbordi, A., \& Esmaeili, M. (2020). Developing a Model of the Impact of Service Quality, Brand's Social Identity and Attachment to the Team on the Loyalty of Football Fans. New Approaches in Sport Sciences, 1(2), 25-43. https://doi.org/10.22054/nass.2019.10533

Beyrami, M. H., \& Najafzadeh, M. R. (2015). The Relationship between Perception of Quality of Services and Spectators Satisfaction in Tractorsazi Tabriz Football Team. International Journal of Economy, Management, and Social Sciences, 4(1), 18-20.

Buning, R. J. (2019). Sport tourism development. Journal of Sport \& Tourism, 23(1), 61-62. https://doi.org/10.1080/14775085.2018.1548814

Chen, N., Wang, Y., Li, J., Wei, Y., \& Yuan, Q. (2020). Examining structural relationships among night tourism experience, lovemarks, brand satisfaction, and brand loyalty on "cultural heritage night" in South Korea. Sustainability (Switzerland), 12(17), 1-23. https://doi.org/10.3390/SU12176723

Dorofeeva, T. (2021). Application of the requirements of international standards and practices ordered by standards to the quality management of physical culture and sports services. Scientific Journal of National Pedagogical Dragomanov University. Series 15. Scientific and Pedagogical Problems of Physical Culture (Physical Culture and Sports), 5(136), 47-53. https://doi.org/10.31392/npunc.series15.2021.5(135).11

Du, J., Jordan, J. S., \& Funk, D. C. (2015). Managing mass sport participation: Adding a personal performance perspective to remodel antecedents and consequences of participant sport event satisfaction. Journal of Sport Management, 29(6), 688-704. https://doi.org/10.1123/JSM.2014-0225 
García-Fernández, J., Gálvez-Ruíz, P., Fernández-Gavira, J., Vélez-Colón, L., Pitts, B., \& Bernal-García, A. (2018). The effects of service convenience and perceived quality on perceived value, satisfaction and loyalty in low-cost fitness centers. Sport Management Review, 21(3), 250-262. https://doi.org/10.1016/j.smr.2017.07.003

Gholipour, N., \& Moradi, E. (2021). The Relationship between Sport Event Quality, Satisfaction , Perceive Value, Loyalty and Behavior Intention: A Meta-Analysis. New Approaches in Sport Sciences, 2(4), 151-178. https://doi.org/10.22054/nass.2021.58974.1085

Hadian, H., Razavi, S. M. H., Boroumand, M. R., \& Amirnejad, S. (2020). Strategies for Developing Economy of Iran's Sports Industry. Annals of Applied Sport Science, 8(2), 2-15. https://doi.org/10.29252/aassjournal.843

Hebles, M., Prado-Gascó, V. J., Llanos-Contreras, O., \& Alguacil, M. (2020). The Influence of Emotion in the Management of Amateur Football Organizations. Frontiers in Psychology, 11. https://doi.org/10.3389/fpsyg.2020.02218

Hussin, A. M. P. H. (2018). Sports Industry Career Opportunities: The Athletes Perception. International Journal of Science and Research (IJSR), 7(6), 1319-1321.

Kaplanidou, K. (2021). Sport events and community development: resident considerations and community goals. In International Journal of Sports Marketing and Sponsorship, 22(1), 53-66. https://doi.org/10.1108/IJSMS-05-2020-0082

Kersulić, A., Perić, M., \& Wise, N. (2020). Assessing and considering the wider impacts of sport-tourism events: A research agenda review of sustainability and strategic planning elements. Sustainability (Switzerland), 12(11), 4473. https://doi.org/10.3390/su12114473

Lee, J. S., \& Kang, J. (2015). Which Senses Matter More? The Impact of Our Senses on Team Identity and Team Loyalty. Sport Marketing Quarterly, 24(4), 225-234.

Lee, M., Kim, D., Williams, A. S., \& Pedersen, P. M. (2016). Investigating the Role of Sports Commentary: An Analysis of Media-Consumption Behavior and Programmatic Quality and Satisfaction. Journal of Sports Media, 11(1), 145-167. https://doi.org/10.1353/jsm.2016.0001

Lee, S., Heere, B., \& Chung, K. (2013). Which Senses Matter More? The Impact of Our Senses on Team Identity and Team Loyalty. Sport Marketing Quarterly, 22(4), 203-213.

Lischka, J. A., \& Messerli, M. (2016). Examining the benefits of audience integration: Does sharing of or commenting on online news enhance the loyalty of online readers? Digital Journalism, 4(5), 597-620. https://doi.org/10.1080/21670811.2015.1068128

Moreno, F. C., Prado-Gascó, V., Crespo Hervás, J., Núñez-Pomar, J., \& Añó Sanz, V. (2016). Predicting future intentions of basketball spectators using SEM and fsQCA. Journal of Business Research, 69(4), 1396-1400. https://doi.org/10.1016/j.jbusres.2015.10.114

Oueslati, K., Hayani, D. B., Nemsi, Z., \& Baklouti, M. (2017). Safety and Service Quality Along With Technology in Mega-Sport Events. International Business and Management, 14(2), 43. www.cscanada.netwww.cscanada.org49. http://dx.doi.org/10.3968/9417

Ranjan, W. (2016). A Review of Sport Events Impact Evaluation Methods. Journal of Tourism, Hospitality and Sports, 19, 31-36.

Savić, Z., Ranđelović, N., Stojanović, N., Stanković, V., \& Šiljak, V. (2018). The sports industry and achieving top sports results. Facta Universitatis, Series: Physical Education and Sport, 15(3), 513. https://doi.org/10.22190/fupes1703513s 
Schnitzer, M., Scheiber, S., Kornexl, E., \& Thöni, E. (2017). Politicians' perspective on the communityrelated impacts of major sports events-a case study for Innsbruck-Tyrol. Sport in Society, 20(7), 880904. https://doi.org/10.1080/17430437.2016.1274552

Silveira, M. P., Cardoso, M. V., \& Quevedo-Silva, F. (2019). Factors influencing attendance at stadiums and arenas. Marketing Intelligence and Planning, 37(1), 50-65. https://doi.org/10.1108/MIP-02-2018-0048

Theodorakis, N. D., Kaplanidou, K. (Kiki), \& Karabaxoglou, I. (2015). Effect of Event Service Quality and Satisfaction on Happiness Among Runners of a Recurring Sport Event. Leisure Sciences, 37(1), 87107. https://doi.org/10.1080/01490400.2014.938846

To-aj, O., \& Suksa-ard, P. (2020). Perceived Benefits of Trademark Infringement Law to Thai Sports Industry. Annals of Applied Sport Science, 8(4), 1-6. https://doi.org/10.29252/aassjournal.884

Wang, Y., Zhang, J. J., Pifer, N. D., \& Kim, M. (2018). Factors affecting the regional strategies for developing and advancing the Chinese sport industry. International Journal of Sports Marketing and Sponsorship, 19(2), 178-193. https://doi.org/10.1108/IJSMS-08-2017-0082

Wymer, W., \& Rundle-Thiele, S. (2016). Supporter Loyalty: Conceptualization, Measurement, and Outcomes. Nonprofit and Voluntary Sector Quarterly, 45(1), 172-191. https://doi.org/10.1177/0899764014564579

Xiao, Y., Ren, X., Zhang, P., \& Ketlhoafetse, A. (2020). The effect of service quality on foreign participants' satisfaction and behavioral intention with the 2016 Shanghai International Marathon. International Journal of Sports Marketing and Sponsorship, 21(1), 91-105. https://doi.org/10.1108/IJSMS-04-2019-0037

Yeung, M. C. H., Ging, L. C., \& Ennew, C. T. (2012). Customer satisfaction and profitability: A reappraisal of the nature of the relationship. Journal of Targeting, Measurement and Analysis for Marketing, 11(1), 24-33. https://doi.org/10.1057/palgrave.jt.5740064

Yürük, P., Akyol, A., \& Şimşek, G. G. (2017). Analyzing the effects of social impacts of events on satisfaction and loyalty. Tourism Management, 60, 367-378. https://doi.org/10.1016/j.tourman.2016.12.016

Zhang, Y., Lee, D., Judge, L. W., \& Johnson, J. E. (2014). The Relationship among Service Quality, Satisfaction, and Future Attendance Intention: The Case of Shanghai ATP Masters 1000. International Journal of Sports Science, 4(2), 50-59. https://doi.org/10.5923/j.sports.20140402.03

Zhuo, L., Guan, X., \& Ye, S. (2020). Quantitative evaluation and prediction analysis of the healthy and sustainable development of China's sports industry. Sustainability (Switzerland), 12(6). https://doi.org/10.3390/su12062184 